Brit. J. vener. Dis. (1961), 37, 257.

\title{
INVOLVEMENT OF THE AORTIC VALVE AND ASCENDING AORTA IN CONGENITAL SYPHILIS*
}

A REVIEW

BY

\author{
F. S. BONUGLI
}

Royal Victoria Hospital, Belfast

\begin{abstract}
A belief in the existence of something usually increases the observed incidence of that phenomenon, and scepticism, which is akin to negativism, is a potent factor in reducing even to the point of elimination the incidence of unacceptable or unbelieved phenomena. An adult patient with congenital syphilis seen in 1952 with dental stigmata, indicating active disease at the time of birth, who also had aortic and aortic valvular disease, encouraged me to look for further examples of cardiovascular complication in prenatal cases. Aortic and aortic valvular disease in lues tarda is believed by some authorities not to occur. Others with equal emphasis declare that it does. A third group believes it may occur as the result of superinfection.
\end{abstract}

Deciding objectively whether or not a patient aged 30 or more was prenatally infected raises questions which at present can be decided only on clinical grounds. The criteria used in these cases are discussed.

Typical Hutchinsonian upper central incisors are pathognomonic of congenital syphilis and indicate active disease at the time of birth. No such teeth were encountered in my series; the upper central incisor teeth in Case 1, described as of Hutchinsonian type, were of the fusiform or oat-shaped variety, but they also showed considerable thickening of the biting edges and some notching. These teeth were more than suspicious but not classical.

The second most pathognomonic sign is probably bilateral interstitial keratitis. If signs of tuberculosis are absent, and if other suggestive stigmata of congenital disease are present, it might then be regarded as diagnostic.

Sabre tibiae have been taken as most suggestive signs of a prenatal infection. The method adopted in assessing a tibia was that suggested by Stokes,

* Paper read in part at the M.S.S.V.D. meeting in Paris on May 12, 1961.
Beerman, and Ingraham (1946a). The tibiae encountered and described as of sabre type, although unequivocal, did not necessarily show radiological changes. Enlargement of the sternal end of a clavicle and rhagades were both regarded as suggestive evidence.

All cases were scrutinized clinically and efforts were made to find evidence for or against a prenatal diagnosis by the investigation, whenever possible, of parents, spouses, sibs, and offspring. It was considered unreasonable to dismiss all histories because some acquired syphilitics are known to be evasive about their earlier experiences. When luetic signs occur in a case with no history or signs of acquired disease it is helpful, at times, to look for prenatal signs and anamnestic evidence. It is accepted that in a substantial percentage of cases the absence of definite congenital signs does not exclude this possibility.

Since my first case in 1952, eight others have come to notice, of which six are specially worthy of attention. None of these additional cases had dental stigmata. My own cases were - with one exceptionliving in a community which is ideal for epidemiological studies. The North of Ireland is closed to immigration, and population movement is less than elsewhere. It would be difficult for clinicians working in an area where population movement is great to collect the type of epidemiological information which I have obtained in most instances by the examination of hospital records and persons related to the patients listed. In spite of the gaps in evidence, the publication of known facts in relation to the less definite cases is, I believe, justified.

It is generally conceded that aortic regurgitation is diagnosable in life and that aortic insufficiency occurring in association with normal mitral sounds or the absence of signs of mitral pathology is unlikely to be of rheumatic origin. $X$-ray evidence 
suggesting linear calcification of the ascending aorta has been demonstrated to indicate that there is or has been a syphilitic involvement of that organ in a very high percentage of cases. It would appear quite probable that this figure may well be as high as 90 per cent. or more; certainly personal experience would not conflict with such a figure. McCann and Porter (1956), who collected evidence from their own experience and from the literature of the diagnostic value of radiologically demonstrable aortic calcification, may be quoted:

\footnotetext{
"A valuable aid to the diagnosis of cardiovascular syphilis has been noted by Schatzki (1942), who pointed out that the presence of calcification of the ascending portion of the aortic arch is highly suggestive of syphilitic aortitis. Wolkin (1954) is also of the opinion that such a finding is a reliable sign of syphilitic aortitis. Jackman and Lubert (1945), who reported sixty radiological examinations in cases of specific aortitis, found linear calcification in the ascending part of the aortic arch in 22.7 per cent., whereas in a control series of 62 cases of arteriosclerosis only 3.2 per cent. had calcium in this portion of the arch. According to Thorner and Carter (1948), calcium was shown radiologically in 39.4 per cent. of 38 consecutive cases of syphilitic aortitis. Thus it would appear that the radiological demonstration of calcification in the ascending part of the aorta is relatively common in specific aortitis, while such a finding is seldom made in other conditions (Thorner and Carter, 1948).

"It is an accepted fact that the bulb and lower portion of the ascending aorta are the centre of the most striking and characteristic pathological changes in syphilis of the vascular system (Stokes, Beerman, and Ingraham, 1946d) which take the form of a supravalvular sclerosis (Martland, 1930). Involvement of the more distal part of the aortic arch is commoner in simple arteriosclerosis, while valvular involvement alone is more suggestive of rheumatic or other non-specific cardiac disease. Gordon, Parker, and Weiss (1942), in a study of 360 cases of chronic syphilitic aortitis, noted that atheromatous changes had taken place over the area affected by the syphilitic lesions, and suggested that chronic syphilitic lesions of the aorta predisposed to the development of local arteriosclerosis. It would thus appear that, whether or not calcification is present in the aortic valve or in the more distal portions of the aortic arch, calcification of the first part of the ascending aorta is highly suggestive of an underlying or predisposing syphilitic lesion. Thus the radiological sign under discussion appears to have a sound pathological basis."
}

\section{Case Reports}

Case 1, a married clergyman aged 36, was referred in November, 1952. He complained of pain in the left mammary area which had been present for about 28 years, and during the last 10 years radiation of this pain down the left arm to the little finger had occurred. These symptoms could not be related to effort and were apparently associated with overwork and emotional factors. Lassitude, irritability, and a vague feeling of heaviness related to the head had been noticed during the previous 6 weeks. Recently while speaking at a public meeting he had collapsed. No previous history of syncope was obtained.

History.- - He had had measles in childhood, frequent attacks of tonsillitis in adolescence, and a history of always being slow to heal. During 1940, while on military service in India, he was given varicose vein injections because of pains in the left tibia but this treatment had not resulted in improvement. The pains became more severe, especially at night so that sleep became impossible but some relief was obtained by the use of wet bandages. His persistent attendance with this symptom at the sick quarter resulted eventually in disciplinary action being threatened. During 1943 an indolent ulcer of the left ankle developed. In 1945 he was referred to Bombay Military Hospital on account of chest pains and massage was prescribed. After demobilization in 1946, he attended the Royal Victoria Hospital, Belfast, with pains in the right groin, and "gravel" was diagnosed. Late in 1948 he had had "abscesses" of the tonsils. Successful treatment with penicillin ointment was given in 1949 by a general practitioner for an indolent skin eruption on the left trochanter area.

He was referred on account of chest pain to the medical out-patient department, Royal Victoria Hospital, Belfast, in 1950; the hospital notes indicate that nothing abnormal was detected, and psychiatric diagnosis was regarded as a likely explanation of his symptoms; the blood pressure at this time was 150/80. In October, 1952, he was referred again to the same hospital with a cardiac murmur detected at a routine emigration medical examination.

Examination.-At the Special Clinic 3 days later the following positive physical signs were noted. The upper incisor teeth were prominent, oat-shaped, slightly notched, and somewhat thickened antero-posteriorly. The degree of notching was modified to an uncertain extent by earlier dental conservative measures. The anterior edge of the left tibia was blunt, the antero-mesial plateau was rounded and roughened, and on deep palpation the middle third was decidedly thickened as compared with the right. An area of skin over the left great trochanter was pigmented and scarred in a manner compatible with previous gummatous change; this scar marked the area successfully treated earlier with penicillin ointment. A small, circular, non-adherent tissuepaper scar was noted above and anterior to the left internal malleolus; this was the site of the indolent ulcer in 1943. The pulse was collapsing, and the apex beat displaced; a typical double aortic diastolic murmur was easily audible. 
The results of special examinations may be summarized as follows:

B.P.: right 170/50, left 170/35.

Serological tests for syphilis: October-December, 1952, repeatedly positive.

Cardiac screening: slignt unfolding of aorta, calcification of the ascending aorta and aortic valve cusps ( Fig. 1).

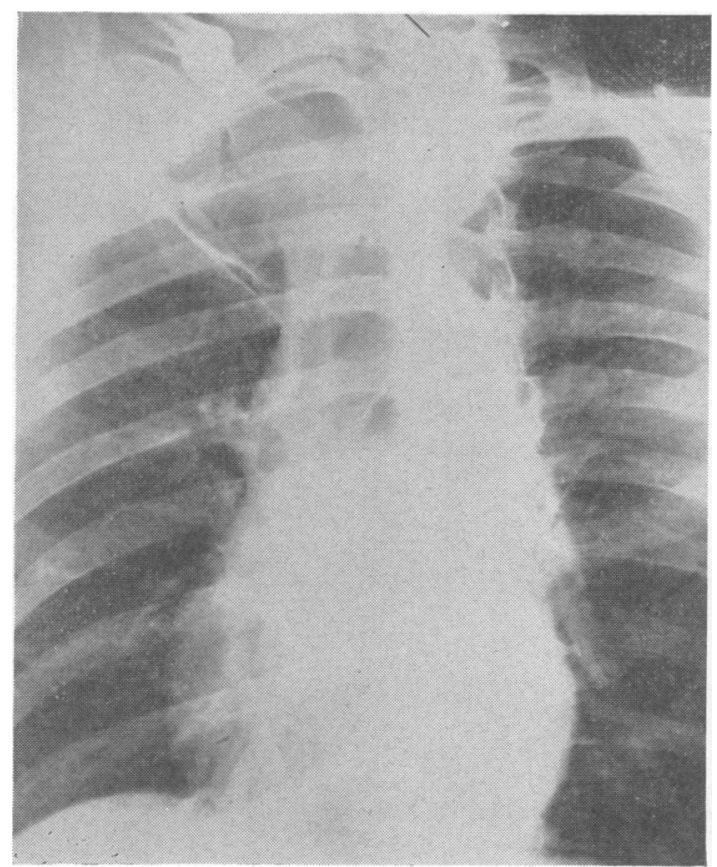

FIG. 1.-Case 1. Radiograph showing linear calcification of the ascending aorta.

X-ray left tibia: tibial bone thicker and heavier than the right.

No evidence of syphilis, clinically or serologically, was found in the patient's spouse and only child. Inquiry into the health record of his sibs eventually revealed that an elder brother, aged 39 , and a younger one, aged 32 , had been treated at my hospital 22 and 21 years earlier. Their records related that the elder brother had been diagnosed, at the age of 17 in January, 1931, as having syphilitic eye disease, his teeth having been described as Hutchinsonian. The younger one had been referred at the age of 11 with interstitial keratitis and Clutton's joints. Both had had positive STS and had been treated, but neither was seen by me as they had emigrated.
Case 2, a widower aged 69, was referred in January, 1954, with a 2-year history of increasing dyspnoea, momentary attacks of double vision, occasional attacks of dizziness, dry cough, and palpitations. Work as a selfemployed hairdresser had been continued until the eve of admission to hospital some days earlier.

Examination.-He was noted to be alert and cheerful, the latter perhaps to a euphoric degree, normally cooperative and well orientated. The corneae showed marked scarring on naked eye examination; lens and slit-lamp examination revealed nothing inconsistent with a diagnosis of healed interstitial keratitis. The nasopharynx showed gross changes; the uvula was absent and the free edge of the soft palate, the tonsillar pillars on both sides, and the pharyngeal wall showed marked alteration and scarring and some deficiency in a manner consistent with previous gummatous inflammation of this area.

The sternal end of the right clavicle was considerably enlarged. The left elbow movements were markedly limited in all directions and muscular wasting was consistent with this impairment of function. Some considerable degree of bowing and thickening of the left tibia was evident.

Veins in both legs were varicose. The radial arteries were thickened, the pulses were equal, regular, and collapsing in type. The apex beat was in the fifth interspace outside the nipple line and the heart appeared clinically enlarged. On auscultation, a soft blowing aortic diastolic murmur conducted down the left. side of the sternum was easily audible. The B.P. was $200 / 100$ in both arms.

Some minor changes were found in the central nervous system, but none in the respiratory and alimentary systems.

The Wassermann reaction and Kahn test were both positive.

History. - The patient had had measles in very early childhood. In 1898, at the age of 13, he first developed eye trouble after being struck on the left eye with a piece of bread. This eye became inflamed and 2 to 3 weeks later the other eye, which had not been injured, also became troublesome; because of bilateral blindness and intense photophobia, hospital admission was arranged, and he was discharged home after 3 months treatment. In 1904, when he was 19 years old, 7 days after a sexual exposure he was diagnosed clinically as having urethritis; treatment with sandalwood oil resulted in "cure" within 3 weeks. This venereal history was admitted without undue reticence. The most careful questioning failed to elicit any evidence which would have suggested that this urethritis represented a syphilitic infection, or that this illness was later complicated by treponemal disease, or that earlier or later he had had an acquired syphilitic infection.

During 1932 injections for varicose veins were received. At the age of 57 , in 1943, after being referred to an ophthalmic hospital, he was given $8 \cdot 6 \mathrm{~g}$. neoarsphenamine, $0.3 \mathrm{~g}$. bismuth metal, $0.45 \mathrm{~g}$. Mapharside, and 
$8 \mathrm{ml}$. collosal mercury. The STS (Wassermann reaction, Fleming, and Sigma) were all positive at intervals during this period. In 1944, in-patient sulphonamide therapy produced rapid disappearance of physical signs suggesting a right basal pneumonia. Available hospital records of this illness indicate that the cardiac sounds were regarded as normal but no record was made of blood pressure readings. During his 66 th year, in 1951 , he spent 4 days in bed under home supervision for pain radiating from the left costal margin to the back and upper abdomen. The pain was described as of gradual onset, colicky in type, and associated with an intense feeling of nausea, although not in any way with vomiting, diarrhoea, dysuria, or the intake of food. No previous or subsequent attacks occurred. Although he recalled extension exercises for the left arm at a very early age, he had no recollection of any disease of the left elbow.

Investigations.-The STS (Wassermann reaction, Kahn, and Sigma) were positive on arrival and subsequently.

Blood urea: $32 \mathrm{mg}$. per cent.

Urine: No albumen, no sugar.

ESR: $8 \mathrm{~mm} . / \mathrm{hr}$.

ECG: T-wave flat.

Cerebrospinal fluid: Clear fluid RBC nil, WBC nil, protein $40 \mathrm{mg}$. per $100 \mathrm{ml}$., globulin nil, W.R. negative, Lange colloidal gold 0000000000 .

X-ray: Left tibia: some cortical thickening on anterior margin (Fig. 2).

Sternal end of clavicle, "the sternal end of the right clavicle shows cystic changes with irregularity of the bone end: the left clavicle is normal" (Fig. 3, opposite).

Left elbow, "the left elbow shows gross irregularity of the joint, the general appearances are those of advanced osteo-arthritic changes."

Heart and aorta, "there is a little ventricular enlargement, some unfolding of the aorta and calcification of the aortic arch, the appearances of the lung fields suggest bronchitis."

Family History.- $\mathrm{He}$ was the youngest of a family of six; three brothers and two sisters had lived to adult life but were all deceased. His mother had died of an unknown cause 3 years after his birth. His father had died at the age of 76 of an unknown cause. His wife had five children, all alive and well, aged 38 to 43 ; no foetal, neonatal, or other loss had complicated her obstetric record; she had died in 1953 some years after suffering from a stroke.

Case 3, a housewife aged 60, was admitted to the Belfast City Hospital in cardiac failure in 1958.

Examination.-She had a systolic and an aortic diastolic murmur associated with a collapsing pulse and a low diastolic blood pressure reading. The sternal end of one clavicle was enlarged and both tibiae were of the sabre type. A marked degree of genu valgum was present.

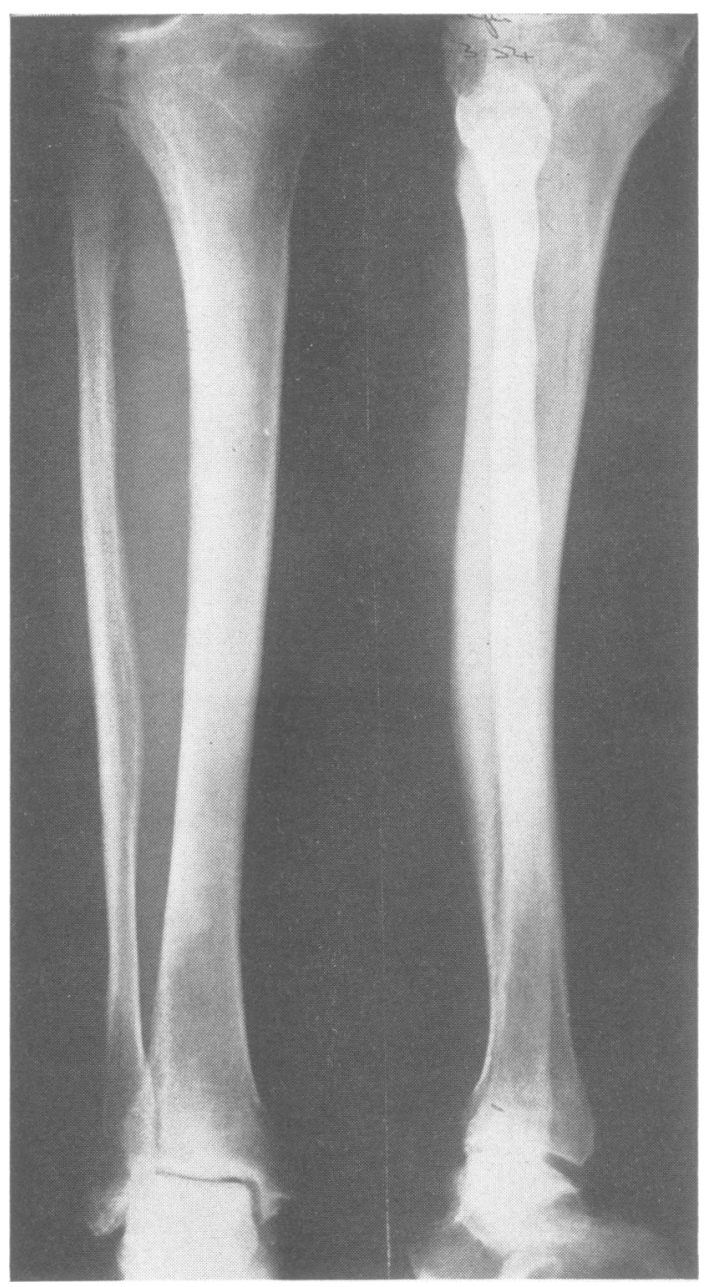

FIG. 2.-Case 2. Radiographs of left tibia showing cortical thickening and tibial bowing.

History.-There was nothing suggestive of rheumatic fever, chorea, blood testing. or injection therapy. $X$-ray studies of the heart and aorta showed a considerable degree of cardiac enlargement and extensive linear calcification of the ascending aorta.

The STS have been consistently positive.

Family History.-Her father had died at the age of 60 and her mother at the age of 53; no hospital documents concerning either of them could be found and their status remains unknown. The mother's obstetric history was, however, much disturbed: six of the nine children died in very early childhood and only two others survived, a son aged 57 and a daughter aged 49. Both these surviving sibs of Case 3 were seen but neither showed any stigmata. Case 3 had had seven pregnancies of which five children survived; the second had terminated in miscarriage at 


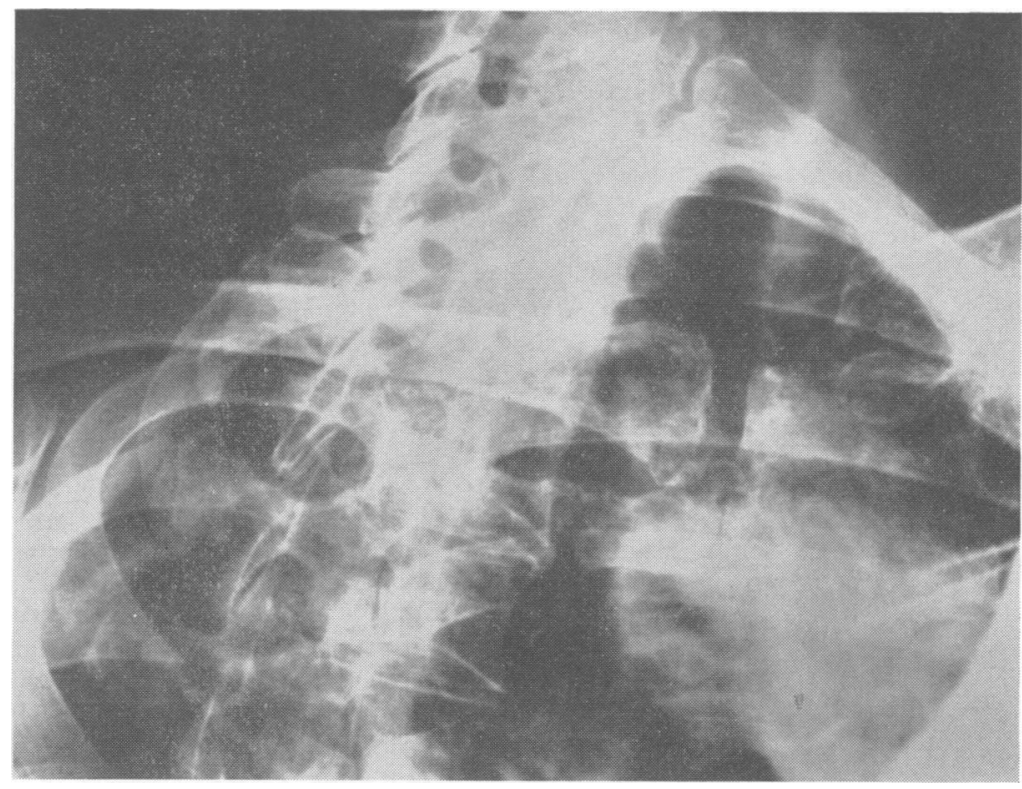

FIJ. 3.-Case 2. Radiograph of sternal ends of clavicles, the right showing cystic changes with irregularity of the bone end. The sternal end of this right clavicle was clinically much enlarged.

3 months. The fifth resulted in twins, one of whom died at one year, the other being stillborn. The five survivors, all female, showed, like their father, no clinical or serological evidence of infection. Four of these five girls were married: one was infertile and the other three had normal obstetric histories.

Case 4, a married labourer aged 56, was first seen early in 1958 in cardiac failure.

Examination.-Auscultation revealed a typical aortic regurgitation murmur; the STS on admission as well as some months earlier gave unequivocal positive results.

History.-There was no record of rheumatic fever, chorea, earlier blood-testing, treatment by injection, or any suggestion of his having had any venereal infection.

The patient died 4 days after admission, and a typical syphilitic valvulitis and aortitis was found on post mortem examination.

Family History.-Investigation revealed that the patient's father had been a patient of mine some years earlier, and the father's case notes showed that he too had positive STS associated with extensive gummatous scarring and leucoplakia. He claimed to have acquired the infection early in marriage from his now deceased wife, ${ }^{*}$ and hospital notes and death certificate confirmed his statement that a son had died of G.P.I. at the age of 24.

This patient's mother's obstetric history had been much disturbed. Her first child died at 13 months, the

*The wife's hospital notes were not available, but her death certificate recorded that she had died of carcinoma of the uterine cervix and did not mention syphilis. second was the present case, the third was alive but declined to co-operate, the fourth died at $13 \frac{1}{2}$ years, the fifth died of G.P.I., and there had been at least one miscarriage and a stillbirth. The patient's spouse in this case was not co-operative.

Case 5, a married labourer aged 43, was referred in 1950 with a typical aortic diastolic murmur and positive STS.

Examination.-Classical signs of tabes dorsalis were present and he later developed a Charcot joint. The sternal end of the right clavicle was unequivocally enlarged.

History.-He denied any previous treatment by injection and any previous blood-testing or history suggestive of rheumatic fever, venereal disease, or chorea. He had had a chronic ulcer on the inner side of his thigh which took several months to heal at age 14; the residual scar was consistent with a gummatous lesion. He also had a history of lightning pains from age 23 .

Family History. -3 years later I saw in consultation a man aged 73 who had been admitted to Purdysburn Mental Hospital, Belfast, and had all the classical, clinical, and pathological signs of G.P.I. This man proved to be the father of Case 5, and I learned that he was also the father of another patient who had come under my care in 1949 (Case 6). This son lived in a village 50 miles from the city and the relationship between Cases 5 and 6 had hitherto been unknown to me.

Case 6, a married policeman aged 46, was admitted to hospital in 1949 with cerebral thrombosis, having been taken ill while visiting the city. He had at that time 
positive serological and cerebrospinal fluid tests, the spinal fluid exhibited a paretic curve and other associated abnormalities indicating active parenchymatous neurosyphilis. He had mild rhagades and an enlarged sternal end of the right clavicle.

History.-He tenaciously denied a past history of venereal disease, previous serological testing, or treatment by injection. Some years later he complained of pain suggestive of coronary disease, and $x$-ray studies revealed extensive linear calcification of the ascending aorta, but his cardiac sounds were (and still are) normal. There was no past history of rheumatic fever or chorea.

Family History.-In 1953, some time after I had seen the father of Cases 5 and 6, their mother, aged 73, was admitted to the Belfast City Hospital with a pulmonary infection and untreated diabetes, and I had the opportunity of seeing her also. The Kahn test was positive and she showed some posterior column changes as well as clinical signs which suggested early Charcot changes in one knee joint. She died 3 days after admission and post mortem examination showed no evidence of syphilis in the organs examined.

Two other sibs of Cases 5 and 6 were examined and found healthy, but a third with a history of chronic invalidism declined to co-operate. The spouses of Cases 5 and 6 had undisturbed personal and obstetric histories and had negative STS.

Case 7, a married dock labourer aged 50, who was referred in 1949, had positive STS and an aortic reflux with unequal blood pressure readings in each arm. His facies was suggestive and rhagades was present.

History.-He had no history of chorea, rheumatic fever, or acquired veneral disease, and there was no previous history of blood testing or of treatment by injection.

Family History.-His parents had died when he was aged 8 , and he had one brother whose whereabouts was unknown but was thought to be alive. Both children had been reared in a workhouse. The patient's wife had had eight pregnancies: one child died at age 6 and another at age $1 \frac{1}{2}$, and the remaining six were alive and well. The wife had neither history nor serological evidence of syphilis.

Case 8, a spinster aged 59, who was a registered blind person, was seen in 1949 with classical signs of tabes dorsalis and aortic regurgitation. Standard tests of the cerebrospinal fluid and serum were persistently positive. and the corneae showed milky scarring.

History.-The eye trouble dated back to the age of 13 and she was first treated for syphilis in 1945. No history of rheumatic fever or chorea was obtained, but she had had a genital sore in her teens and was unable, probably on account of deep feelings of guilt, to give any useful account of this event.

Family History.-This patient has no siolings and tenaciously regards herself as having an acquired infection. She exhibits no other definite signs of congenital disease and is unwilling to co-operate about the attendance of her mother. A Mantoux 1/1,000 was negative.

Case 9, a married man aged 38, was not seen personally. He died in Fulham Hospital, London, of a thoracic aneurysm in 1950. A letter from this hospital revealed the above and stated that "congenital infection was most likely as the disease had been first suspected at the age of 21 ". The STS were positive. My interest in this case was aroused when the father was referred to me in 1952 . He had contracted syphilis before marriage and was first treated in 1922. His STS were consistently positive, and he exhibited signs of tabes dorsalis and had a large abdominal aneurysm. He reported that his son had died of an aneurysm, and subsequent inquiry revealed the information quoted above. Clinical and serological examination of this patient's mother revealed no definite evidence of syphilis. She had one other son, who declined to attend, and no miscarriages or stillbirths.

\section{Discussion}

The oldest patient (Case 2, aged 69) requires some comment. He had marked pharyngeal scarring and advanced osteo-arthritis of the left elbow, but no memory of any throat or elbow complaint. He could, however, recall having had, at a very early but uncertain age, extension exercises for the left arm. These destructive processes very early in life, a history of bilateral interstitial keratitis at age 13, and objective clinical and radiological evidence of tibial and clavicular stigmata add up to a strong case for prenatal infection. The throat lesion could have been caused by a tubercular process, but 60 years ago a patient with tuberculosis of the throat of the degree which must have existed here would not have survived. The elbow lesion can, in my opinion, be described as a "von Gies joint" (Stokes and others, 1946a). This patient admitted to having a venereal urethritis at the age of 17 which settled in 2 weeks on sandalwood oil treatment; no other unusual tissue reaction was noted at that time. There was no history of acquired syphilis and no history of treatment by injection except for varicose veins before the age of 57. The patient gave no indication at any time that would tend to classify him as an unreliable historian. All the available evidence points, in spite of his age, to his aortitis being due to congenital syphilis. The children of this case were not examined, and the obstetric history of his wife had been undisturbed. 
McDonald (1932) pointed out the rarity of pathological case records of aortitis in lues tarda, and described a case of acute liver necrosis in a congenital syphilitic aged 9 who had died while undergoing arsenical treatment. This child had interstitial keratitis in July, 1931, and was found at autopsy to have syphilitic mesaortitis. The father of this child had been under treatment since 1925 for tertiary syphilis and the mother had a history of stillbirths and early deaths of her children. 2 years later McDonald (1934) presented a further study of syphilitic aortitis encountered at autopsy in eleven additional patients up to the age of 30 . Four of these, aged 19 to 22 years (average 20), he considered to be congenital (Table: Cases A to D). Five others, aged 24 to 30 years (average 28), he classified largely on account of their age as possibly congenital. The two remaining cases were stated to have a past history of acquired syphilis.

One was a male alcoholic, aged 28 , with a past history of syphilis and gonorrhoea, and the other was a female prostitute, aged 20, with a definite history of primary syphilis.

McDonald also cited eight other cases previously reported, whose ages varied from 7 to 20 years (average 14); these included his own case quoted in 1932.
Macfarlane, Swan, and Irvine (1956) described two female cases of congenital cardiovascular syphilis which were found among 1,330 syphilitic patients referred for cardiological investigation. Of 202 patients (15 per cent.) with cardiovascular disease, three were considered to have congenital infections:

One, aged 34, had Hutchinsonian teeth, an oldstanding healed keratitis, and a positive low-titre Wassermann reaction. This patient showed acceptable evidence of aortitis, but no evidence of valvulitis.

The second, aged 45, gave "the strongest possible evidence of syphilitic aortitis with involvement of the aortic valve in a patient with congenital syphilis". The criteria for congenital syphilis in the second case were apparently treatment during infancy and chronic choroiditis. This case had aortic incompetence as well as a dilated calcified ascending aorta.

The third had a gross lesion of the aortic valve but in addition rheumatic mitral valve disease; she was not therefore regarded as a proved case of cardiovascular syphilis.

It is significant to note that two of the cases listed by McDonald (1934), neither of which was on his congenital list, showed anatomical evidence of rheumatic heart disease in addition to signs of syphilitic aortic involvement. These cases were the

TABLE

SUMMARY OF FOUR CASES OF CONGENITAL SYPHILIS ALL SEEN IN 1932 (McDONALD, 1934)

\begin{tabular}{|c|c|c|c|c|c|c|}
\hline $\begin{array}{l}\text { Case } \\
\text { No. }\end{array}$ & Sex & $\begin{array}{c}\text { Civil } \\
\text { Status }\end{array}$ & $\begin{array}{c}\text { Age } \\
\text { (yrs) }\end{array}$ & Occupation & Evidence for a Diagnosis of Syphilis & $\begin{array}{l}\text { Evidence for a Prenatal Infection, includ- } \\
\text { ing Status of Parents, Spouse, and Sibs } \\
\text { where Known }\end{array}$ \\
\hline A & Male & $\begin{array}{c}\text { Not } \\
\text { Stated }\end{array}$ & 22 & $\begin{array}{l}\text { Braille } \\
\text { copy-typist }\end{array}$ & $\begin{array}{l}\text { Wassermann reaction positive } \\
\text { A.S.T., 1927-32 } \\
\text { Typical syphilitic changes in first } 2 \mathrm{~cm} \text {. of } \\
\text { aorta, involving sinuses of Valsalva and } \\
\text { coronary orifices, thickening of valve } \\
\text { and attachments with vascularization } \\
\text { Fibrosis in media, cuffing of vasa vasorum } \\
\text { in media, with lymphocytes and plasma } \\
\text { cells } \\
\text { Complicated by rheumatic endocarditis } \\
\text { with mitral valve involvement }\end{array}$ & $\begin{array}{l}\text { Hutchinsonian teeth } \\
\text { Almost totally blind } \\
\text { Past history of I.K. } 1917 \text { (apparently } \\
\text { bilateral) } \\
\text { Rough thickened tibial bones with for- } \\
\text { ward curvature } \\
\text { Only child } \\
\text { Mother died aged } 48 \text { of cerebral haemor- } \\
\text { rhage } \\
\text { Father "alive and well" }\end{array}$ \\
\hline B & Male & $\begin{array}{l}\text { Not } \\
\text { stated }\end{array}$ & 21 & $\begin{array}{l}\text { Ice cream } \\
\text { vendor }\end{array}$ & $\begin{array}{l}\text { Brought in dead. } \\
\text { Aortic cusps inflamed, mitral valve normal } \\
\text { First, second, and third parts of aorta } \\
\text { showed gross syphilitic aortitis } \\
\text { Coronary orifices occluded } \\
\text { Histology confirmed macroscopic findings }\end{array}$ & $\begin{array}{l}\text { Father tabetic } \\
\text { Sister's status shown as Case C }\end{array}$ \\
\hline C & Female & $\begin{array}{l}\text { Not } \\
\text { stated }\end{array}$ & 19 & $\begin{array}{l}\text { Domestic } \\
\text { servant }\end{array}$ & $\begin{array}{l}\text { Brought in dead, having collapsed on } \\
\text { hearing news of brother's death } \\
\text { Autopsy revealed syphilitic aortitis with } \\
\text { coronary stenosis } \\
\text { No histology }\end{array}$ & $\begin{array}{l}\text { Sister of Case B } \\
\text { Father tabetic }\end{array}$ \\
\hline $\mathbf{D}$ & Female & Single & 19 & None & $\begin{array}{l}\text { Aortic cusps thickened and opaque. } \\
\text { First } 2 \text { in. of aorta and an area of descend- } \\
\text { ing aorta showed macroscopic evidence } \\
\text { of syphilitic aortitis } \\
\text { Coronary orifices narrowed } \\
\text { Histology confirmed }\end{array}$ & $\begin{array}{l}\text { Virgo intacta } \\
\text { Facies suggestive of congenital syphilis } \\
\text { Nose saddle-shaped } \\
\text { Hutchinsonian teeth } \\
\text { Rhagades present } \\
\text { No details of parents }\end{array}$ \\
\hline
\end{tabular}


only two (of which one had a past history of gonorrhoea and syphilis) out of the eleven described by McDonald in which a clinical diagnosis of aortic valvular lesion was made; this notwithstanding the fact that, in the majority, there were gross changes in the first part of the aorta and some degree of coronary occlusion. Clinical data however were not available in three cases brought in dead. In two instances (Table: Cases A and D), a clinical diagnosis of lues tarda was made. McDonald (1932) also quoted fourteen references published between 1911 and 1927 to the clinical diagnosis of congenital aortitis in children and adults up to the age of 40 years. One case, in a patient aged 40 , was described by Fournier (1912).

Gjestland (1955a), in his re-analysis of the BoeckBruusgaard material on untreated syphilis, stated that "In patients aged 15 to 39 at infection the average duration of infection at the time of recognition of cardiovascular syphilis, irrespective of form, was 31.4 and 31.7 years in males and females respectively". Such an incubation period is likely to reduce the possibility of encountering useful dental stigmata in studies of this type. Gjestland (1955b), in the same study, stated that "Of the total of 209 autopsied patients, cardiovascular syphilis in one form or another was diagnosed in little more than one-fourth of the cases $(26 \cdot 3$ per cent.)". The experience of McDonald was similar.

These statements might perhaps be interpreted as cautioning against dogmatic statements about the absence of aortic disease in any particular type of syphilitic patient, and also as encouraging those searching for cardiovascular lesions. However, some experienced physicians have denied the possibility of cardiovascular lesions in lues tarda. Nicol (1950) stated that "valvular lesions do not occur in congenital syphilitics"; this comment was in reply to that of Laird (1950) who held the contrary view. Quoting Gjestland (1955c):

"In a monograph on the subject Hinrichsen (1943) stated that myocardial lesions might be present in infantile congenital syphilis, but that valvular syphilitic manifestations had never been demonstrated in late congenital syphilis. In a study of 82 children with congenital syphilis treated with salvarsan (and in some cases combined with mercury or bismuth) during the period 1918-1924 and re-examined in 1942-1944, Aggerbeck (1949) found only one with definite cardiovascular disease. The diagnosis was aneurysm of the ascending aorta and hemiplegia (vascular syphilis of the brain?). Duration of infection was estimated at about 21 years.
"We, have no reliable figures on frequency relative to age at infection. .... We know that its occurrence in congenital syphilis is not common. McCulloch (1930), in a study of 939 children with congenital syphilis, found only five cases with cardiovascular disease among the 498 who were over 2 years of age, and in all instances the heart disease was of rheumatic origin. Of the 441 under 2 years of age, 32 died and in three of these syphilitic heart disease was demonstrated, while the 409 others showed no symptoms or signs of cardiovascular involvement."

\section{Again quoting Gjestland (1955d):}

"In this connexion it is of interest to note that no case of cardiovascular syphilis was found among the 66 persons in our series who acquired their disease before the age of 15 . It must be emphasized that the majority of them were infected at ages $0-4$. With the relatively small number observed, we are in no position to state that cardiovascular syphilis does not occur in such patients, but our findings suggest that these complications are rare. Thus, using cardiovascular involvement as an index, it seems that, in those infected in utero and in those infected during early childhood, the syphilitic infection takes a considerably milder course than would be expected."

In the present series, it cannot be stated emphatically whether patients without diagnostic stigmata were originally infected before birth or during childhood. Separate related and unrelated infections in parents and issue do occur, so that coincidental involvement of both parties has to be considered. Interesting figures relating to the incidence of asexually-acquired syphilis contracted from household and family contacts as well as sexuallycontracted syphilis in childhood have been collected by Rees (1954). The ratio of acquired syphilis in childhood to congenital syphilis seems to have ranged from as high as $1: 7$ (Fruhinsholz, 1903) to as low as 2.8:100 (asexually-acquired syphilis in children only: Eisenberg, Plotke, and Baker, 1949). About the same time, Nabarro (1954a) expressed the view that the ratio of congenital to acquired syphilis in childhood is about 20:1.

The field of superinfection and re-infection in syphilology is well recognized as one in which clinicians and others must tread warily. Clinicians, however, must have opinions, and the statements made in relation to aortic lesions in adult congenital syphilitics provoke speculation, as well as the reconsideration of one's own views and experiences.

Since Jonathan Hutchinson's time, superinfection has been postulated as a possible event in the lives of 
syphilitics. This cannot be applied generally to all congenitals or to congenitals only, nor can it be permitted in our present state of knowledge to rob congenitals of their status. The incidence of second infection and superinfection is not known and must vary with factors in organism, host, and environment.

Assuming that re-infection or superinfection may occur in the untreated early in life, the lesions would most likely - if detected-be diagnosed as part of the original infection; in other words, they would be inconspicuous as far as re-infection is concerned, and little history of this is likely to be obtained. It is generally conceded that these events are unlikely. If re-infection or superinfection occurs later in the life of the untreated, at a time when sensitivity to the spirochaete has been acquired, the initial lesion would, in all probability, take on the more conspicuous characteristics of a gummatous tumour or ulcer. In our culture, the main factor in re-infection or superinfection would be illicit sexual exposure by the subject or his spouse, and after puberty lesions of this type would presumably occur at the usual sites of primary sores, and would be even more conspicuous than a primary chancre.

According to Allison (1942), Hahn (1941) completed a review of cases of re-infection in congenital syphilis in the literature and expressed the view that none could be accepted as proved in the light of modern knowledge. In addition, Hahn reviewed 104 probable or possible re-infections of congenital syphilitics listed in the diagnosis file of the Syphilis Clinic of the Johns Hopkins Hospital, and of these he could accept only two without question. Allison then described two other cases of secondary infection in congenitals from the Johns Hopkins Hospital. All four (two of Hahn's and two of Allison's) were coloured children who had been previously treated. Allison points out that a second infection may apparently occur in congenital cases other than those treated early in the course of the first infection. These observations: "suggest a possible difference between the immunity developed by congenitally syphilitic individuals and that which develops in those who do not become infected until after birth".

\section{Quoting Willcox (1960):}

\footnotetext{
"Grin (1953), struck by the fact that in Yugoslavia the incidence of gummata was high in those areas where the incidence of early lesions of endemic syphilis was also high, considered that superinfection might well be an explanation. Murray, Merriweather, Freedman, and de Villiers (1956) showed pictorial examples of gumma of the breast in women with long-standing latent syphilis
}

believed to have been superinfected by other children who had recently contracted the endemic disease. The view that gummata may arise from superinfection of latent cases (and indeed may therefore be an indication of activity of an endemic focus) is now widely held (Grin, 1953; Guthe and Luger, 1957)".

In 15 years I have, as far as I can remember, seen only one case of gummatous lesion on the genitalia (in a middle-aged promiscuous chronic syphilitic male variety artist who had a gumma of the glans penis). This indicates that superinfection was an unlikely explanation of any of my own cases. Stokes and others (1946c), quoting their own work and that of others, indicated that active skin and mucous membrane lesions played a fairly minor role as presenting symptoms in tardive syphilitic children (over 3 years of age) seeking medical advice in the series listed. One exception was a $17 \cdot 6$ per cent. incidence of active skin and mucous membrane lesions (8.1 per cent. condylomata) found by Howles (1939). It is notable that Howles gained his experience in New Orleans, Louisiana, and that $69 \cdot 3$ per cent. of these cases were coloured children. The next highest figure for these presenting symptoms was 5.6 per cent. Stokes and others reported that none of their 202 cases presented this way. These percentages would probably be smaller still if children over 5 years of age rather than children over 3 years were included. Nabarro (1954b) denied having ever seen a case of re-infection and superinfection. Halley and Wasserman (1928), reviewing the question of a second infection in acquired syphilitics, found that 97.8 per cent. of all secondary infections occurred in individuals who were treated early in the course of their first infection.

With two exceptions, the history and physical findings in the cases personally seen, gave rise to no suspicion of acquired disease-either first, second, or superinfection. The chief exception is Case 8, who had evidence of old-standing healed interstitial keratitis; she had a history of genital sore in her late 'teens, but no informative description of this lesion (which was associated with guilt feelings) could be obtained. She regarded herself as having acquired the disease and was unwilling to believe otherwise or to co-operate about the attendance of her mother. Her belief was possibly reinforced by management elsewhere, some treatment having been given to her 4 years before I saw her. One cannot, of course, credit this or any patient with diagnostic acumen, but it is for this reason, together with the absence of congenital signs other than bilateral interstitial keratitis, that this case is placed second to last on the list and is regarded only as a possible instance of congenital syphilis. My Case 5 had a gummatous 
type of lesion at the age of 14 on the inner side of the right thigh; this was not situated particularly near the genitals and occurred in an unlikely area for a primary chancre; it was not associated with sexual exposure.

McDonald (1934), discussing the existence of aortic lesions in adult congenital syphilitics, suggested reinfection or superinfection as a possible explanation:

"If it be the case that the tertiary stage of acquired syphilis is the period in which superinfection is most likely, i.e. some 15 or 20 years after the primary infection, it seems reasonable to suggest that a heredo-syphilitic, after the age of puberty, may be not only more highly susceptible to Treponema pallidum than the descendant of a healthy stock, but also more likely to suffer rapid and progressive aggravation of aortic lesions."

This author, however, makes no observations on the pathogenesis of the last part of his statement, which appears to take the offending organism without interruption from a superinfected lesion, presumably in the skin or mucous membrane, to the aorta itself. It is probable that, if superinfection does take place, it occurs most readily when the original infection has had time to settle into a state of late latency. If re-infection "takes" in such cases, it may presumably have one of a number of results. Three of these are:

(a) To be completely localized,

(b) To cause a systemic invasion which fails to persist,

(c) To cause a spirochaetaemia, which may give rise (then, later, or recurrently) to lesions of a destructive or non-destructive type in any of several tissues.

In my experience not all late lesions necessarily destroy the vital elements of the tissue in which they occur. It is probable that there is an added potential danger to vital tissue such as the aorta only in the third eventuality. Superinfection has already been considered a most unlikely event in untreated cases in an advanced community. Nor is there any reason to suppose that the aorta especially attracts attack in cases of superinfection. McDonald may have been entertaining a view of the superinfection mechanism somewhat different to that generally held.

The incidence of cardiovascular complications in untreated cases of congenital syphilis may be lower than in untreated cases of acquired syphilis, but it seems likely, in view of the trouble that has to be taken to produce anamnestic evidence and the frequency with which this seems necessary, that many patients-through expediency or lack of interest-are not investigated but simply credited by default to the acquired form of the disease or to rheumatic infection. It is also evident that it is all too easy to classify cases of congenital syphilis with reasonably definite clinical signs, as well as those with none, incorrectly. Not one of my cases were so suspected before being referred.

The number of aortic and aortic valvular lesions diagnosed in congenital syphilitics is probably also reduced by other additional factors:

(a) The anatomical rate as in acquired disease is very much greater than the clinical rate,

(b) Anamnestic facts are not always obtainable even if sought,

(c) Spontaneous "cure" of aortitis in cases of congenital syphilis probably occurs,

(d) Only about 80 per cent. are sero-positive when they develop aortic signs,

(e) An erroneous impression exists that the medical history of all syphilitics is not to be trusted,

$(f)$ An attitude of mind that denies the existence of this entity,

$(g)$ The view frequently held that the finding of a positive Wassermann reaction is the end of rather than a mid-point in a medical investigation.

\section{Summary and Conclusion}

Nine patients aged 36 to 69 (eight personally seen) and six others aged 19 to 45 extracted from two sources in the literature with evidence of syphilitic cardiovascular disease have been described.

Twelve of these fifteen cases had clinical or pathological evidence of syphilitic valvulitis. One had syphilitic aortitis without definite evidence of valvular change. In two with thoracic aortic lesions, not personally seen, the condition of the aortic valve was not described.

In thirteen of the fifteen patients, a case based on the strongest possible epidemiological evidence can be made out in favour of a congenital infection. Cases 8 and 9 may be classified as possible congenitals.

There is good evidence that patients with congenital syphilis, like those with acquired syphilis, do develop (at a great variety of ages and at various times after infection) aortic and aortic valvular lesions.

This subject is important from the epidemiological, domestic, scientific, and medico-legal aspects.

My grateful thanks are due to Dr. H. E. Hall, late senior consultant to the Venereal Disease Department, Royal Victoria Hospital, Belfast, also to Dr. D. C. Porter, senior consultant to the Radiology Department, 
Royal Victoria Hospital and Ulster Hospital for Children and Women, Belfast, for radiological studies on most of Cases 1-9.

\section{REFERENCES}

Allison, S. D. (1942). Amer. J. Syph., 26212.

Aggerbeck, I. (1949). “Cardio-vasculaer lues og dens tidlige prophylaxe" (English summary). Rosenkilde og Baggers Vorlag, Copenhagen.

Eisenberg, H., Plotke, F., and Baker, A. H. (1949). J. vener. Dis. Inform., 30, 7.

Fournier, A. quoted by Fournier, E. (1912). "Syphilis héréditaire de l'âge adulte”. Masson, Paris. Cited by Stolkind (1920).

Fruhinsholz, A. A. (1903). Rev. Hyg. Méd. infant., 2, 1.

Gjestland, T. (1955a). Acta derm.-venereol. (Stockh.), 35, Suppl. 34, p. 327. (1955b). Ibid., p. 325

(1955c). Ibid., p. 261. (1955d). Ibid., p. 303 .

Gordon, W. H., Parker, F. jr., and Weiss, S. (1942). Arch. intern. Med., 70, 396.

Grin, E. I. (1953). "Epidemiology and Control of Endemic Syphilis", Wld Hlth Org. Monogr. Ser. No. 11. W.H.O., Geneva.

Guthe, T., and Luger, A. (1957). Dermatologica (Basel), 115, 248.

Hahn, R. D. (1941). Amer. J. Syph., 25, 200.

Halley, C. R. L., and Wasserman, H. (1928). Arch. intern. Med., 41, 843.

Hinrichsen, J. (1943). Amer. J. Syph., 27, 319.

Howles, J. K. (1939). Sth. med. J., 32, 940.

Jackman, J., and Lubert, M. (1945). Amer. J. Roentgenol., $53,432$.

Laird, S. M. (1950). (Discussion.) Brit. J. vener. Dis., 26, 123.

McCann, J. S., and Porter, D. C. (1956). Brit. med. J., 1, 826.

McDonald, S. jr. (1932). Brit. J. vener. Dis., 8, 263. (1934). Ibid., 10, 183.

Macfarlane, W. V., Swan, W. G. A., and Irvine, R. E. (1956). Brit. med. J., 1, 831.

McCulloch, H. (1930). Amer. Heart J., 6, 136.

Martland, H. S. (1930). Ibid., 6, 1.

Murray, J. F., Merriweather, A. M., Freedman, M. L. and de Villiers, D. J. (1956). Bull. Wld Hith Org., $15,975$.
Nabarro, D. (1954a). "Congenital Syphilis”, p. 441. Arnold, London.

- (1954b). Ibid., p. 117.

Nicol, C. S. (1950). (Discussion.) Brit. J. vener. Dis., 26, 124.

Rees, E. (1954). Ibid., 30, 19.

Schatzki, R. (1942). New Engl. J. Med., 227, 18.

Stokes, J. H., Beerman, H., and Ingraham, N. R. jr. (1946a). "Modern Clinical Syphilology", 3rd ed., p. 1128, fig. 830. Saunders, Philadelphia. (1946b). Ibid., p. 1132. (1946c). Ibid., p. 1113. (1946d). Ibid., p. 900 .

Stolkind, E. J. (1920). Brit. J. Child. Dis., 17, 126 (cited by McDonald, 1932).

Thorner, M. C., and Carter, R. A. (1948). Amer. Practit. (Philad.), 2, 301.

Willcox, R. R. (1960). Brit. J. vener. Dis., 36, 83.

Wolkin, A. (1954). Radiology, 62, 101.

La valvule aortique et l'aorte ascendante dans la syphilis congénitale.

RÉSUMÉ

L'auteur décrit 9 malades âgés de 36 à 69 ans (dont 8 furent examinés par l'auteur en personne) et six malades àgés de 19 à 45 ans (cas empruntés à la littérature) qui présentaient des symptômes de syphilis cardiovasculaire.

Sur ces 15 cas, 12 présentaient des signes cliniques ou pathologiques de valvulite syphilitique. Un autre avait l'aortite syphilitique sans symptôme de lésion de la valvule. Chez deux cas avec des lésions aortiques thoraciques (non examinés par l'auteur), l'étât de valvule aortique n'etait pas indiqué.

Chez 13 des 15 malades, les faits épidemiologiques attestent l'existence d'une infection congénitale; les deux autres cas (Nos. 8 et 9) peuvent être classifiés sous la rubrique de "syphilis congénitale possible".

Il est vrai que les cas de syphilis congénitale, comme ceux de syphilis acquise, présentent de temps en temps les lésions de l'aorte et de la valvule.

Ce sujet est important du point de vue épidemiologique, domestique, scientifique et légal. 